\title{
Polycyclic aromatic hydrocarbons in dust from the indoor environment of Qatar
}

Mohamed M. Kotb*, Balint Alfoldy, Oguz Yigiterhan, A. E. Elnaiem, Hassan M. Hassan, Jeffrey P. Obbard

Qatar University, Environmental Science Center (ESC), P.O. Box 2713, State of

Qatar

*Email: mmkotb@qu.edu.qa http://dx.doi.org/

10.5339/qproc.2016.qulss.36

(C) 2016 Kotb, Alfoldy, Yigiterhan, Elnaiem, Hassan, Obbard, licensee HBKU Press. This is an open access article distributed under the terms of the Creative Commons Attribution license CC BY 4.0, which permits unrestricted use,

distribution and reproduction in any medium, provided the original work is properly cited.

\section{ABSTRACT}

Polyaromatic Hydrocarbons (PAHs) concentrations in dust trapped on air conditioning unit filters operating in residential and workplace locations in Doha, Qatar were sampled and measured. Fourteen samples were collected and their PAH congener profile were quantified using gas chromatographymass spectrometry (GC-MS). The results showed that the medians of $\Sigma \mathrm{PAH}_{16}$, which include seven carcinogenic components $\left(\Sigma \mathrm{PAH}_{7}\right)$, were $214.7 \mathrm{ng} \mathrm{g}^{-1}$ and $129.2 \mathrm{ng} \mathrm{g}^{-1}$ of dust respectively for the residential samples, and $224.4 \mathrm{ng} \mathrm{g}^{-1}$ and $137.9 \mathrm{ng} \mathrm{g}^{-1}$ respectively for dust samples collected in an office workplace environment. Among all samples, benzo (b) fluoranthene (BBF) and benzo (a) pyrene (BAP) were the dominant congeners in both the residential and workplace samples, representing $18.2 \%$ and $16.9 \%$ of the $\Sigma \mathrm{PAH}_{16}$, respectively. Factors of correlation were calculated for various PAHs, and showed that lighter molecular weight PAHs have a significant positive correlation with heavier congeners within the residential samples, while workplace samples showed a negative correlation with BAP, Indeno (1,2,3-cd) pyrene (IND), and Dibenz (a,h) anthracene (DBA). Benzo (a) pyrene equivalent (BAPe) was used to assess the risk of human exposure to PAH inhalation. BAPe estimates for residences sampled averaged $0.019 \mu \mathrm{g} \mathrm{g}^{-1}$, with a maximum of $0.063 \mu \mathrm{g} \mathrm{g}^{-1}$ of dust, while workplace estimates averaged at $0.056 \mu \mathrm{g} \mathrm{g}^{-1}$ with a maximum of $0.148 \mu \mathrm{g} \mathrm{g}^{-1}$. Source apportionment assessment indicated that most residential and workplace PAHs samples have a pyrogenic origin with few showing evidence of petrogenic origins. All quantified PAHs concentrations and estimated BAPe in Qatar indoor dust samples are well below reported values elsewhere in the world.
Cite this article as: Kotb MM, Alfoldy B, Yigiterhan O, Elnaiem AE, Hassan HM, Obbard JP. Polycyclic aromatic hydrocarbons in dust from the indoor environment of Qatar. QScience Proceedings: Vol. 2016, QULSS 2016: Biodiversity, Sustainability and Climate Change, with Perspectives from Qatar, 36. http://dx.doi.org/10.5339/qproc.2016.qulss.36 